\title{
Radiological changes in men and women with ankylosing spondylitis
}

\author{
J. T. GRAN ${ }^{1}$ G. HUSBY ${ }^{1} M$. HORDVIK,${ }^{2}$ J. ST $\emptyset R M E R,{ }^{2}$ AND \\ Ø. ROMBERG-ANDERSEN ${ }^{3}$
}

From the Departments of ${ }^{1}$ Rheumatology and ${ }^{2}$ Radiology, Institute of Clinical Medicine, University of Troms $\varnothing$, Troms $\varnothing$, and ${ }^{3}$ Revmatismehuset in Trondheim, Trondheim, Norway

SUMmARY The radiographic changes of ankylosing spondylitis were studied in 50 females and 82 males. There was a tendency for the males to have more severe arthritic changes in the sacroiliac joints than the females, but the difference did not reach statistical significance. Males significantly more often had radiological involvement of the lumbar spine. More restricted lumbar mobility, total spinal flexion, and chest expansion were found in males with $x$-ray changes in the lumbar spine than in males without such features. No such significant difference could be found in females. These findings may indicate a less severe disease as judged roentgenologically in females than in males. The correlations between restriction of chest and spinal mobility and $x$-ray changes were stronger in males.

Ankylosing spondylitis (AS) was formerly considered to be an inflammatory rheumatic disorder of the male sex. ${ }^{1.2}$ It was long accepted that males constituted more than $90 \%$ of the patients with $\mathrm{AS},{ }^{1-3}$ even though contemporary studies showed a male to female ratio of $3 \cdot 5: 1$ to be more likely. ${ }^{4}$ However, several recent studies of blood donors ${ }^{5}$ have suggested a sex ratio of approximately one, although these estimates have yet to be confirmed by epidemiological surveys. There are probably many reasons for the suggested underestimation of this disease in females. ${ }^{5}$ The clinical manifestations may be different in males and females, possibly with a more favourable prognosis among females..$^{6-10} \mathrm{We}$ have, however, recently compared males and females with $\mathrm{AS}^{11}$ and were somewhat surprised to find no fundamental clinical differences between the two sexes.

In the present study we sought possible differences between men and women with AS as expressed by radiological features of the disease. As definite arthritic $x$-ray changes are crucial for the diagnosis of $\mathrm{AS},{ }^{12}$ any difference in radiological abnormalities between males and females might explain a presumed reluctance of clinicians to diagnose $\mathrm{AS}$ in females.

Accepted for publication 19 March 1984.

Correspondence to J. T. Gran, MD, Lillehammer Sanitetsforenings Revmatismesykehus, 2600 Lillehammer, Norway.

\section{Materials and methods}

Patients. Records of all AS patients attending the Department of Rheumatology, Regional Hospital of Troms $\emptyset$ during the period between 1979 and 1982 were reviewed. Hospital records contained sufficient information for the purpose of the present study in 82 cases of AS ( 22 females and 60 males), and these were therefore included in the analysis. In addition, an epidemiological survey was undertaken in Troms $\varnothing$ municipality in 1979 , and the 22 males and five females with definite AS identified through this survey were also included. In order to obtain a sufficient number of female AS patients for the investigation 23 additional females with AS consecutively seen at Revmatismehuset, Trondheim, Norway were included. Thus, altogether 50 females aged 23-63 years (mean age 40.6 years) and 82 males aged $20-59$ years (mean age $36 \cdot 7$ years) were studied (Table 1). The mean disease duration was $15 \cdot 3$ years (range 2-45 years) in females and $13 \cdot 7$ years (range 1-41 years) in males (Table 1).

Clinical examination. The mobility of the lumbar spine was measured by Schober's test, ${ }^{13}$ and total spinal mobility (except the cervical spine) was determined by spondylometry. ${ }^{14}$ Chest expansion was measured according to accepted standards. ${ }^{15}$ The age at onset of AS was given by the patients themselves. Because of possible observer variation between clinicians at the two hospitals, the results of 
Table 1 Disease duration, age, and frequency of HLA-B27 in men and women with $A S$

\begin{tabular}{lrlll}
\hline No. & $\begin{array}{l}\text { Mean disease } \\
\text { duration } \\
\text { (years) }\end{array}$ & $\begin{array}{l}\text { Mean age } \\
\text { (years) }\end{array}$ & $\begin{array}{l}\text { Frequency } \\
\text { of B27 } \\
(\%)\end{array}$ \\
\hline Males & 82 & $13 \cdot 7(1-41)^{*}$ & $36 \cdot 7(20-59)$ & 90 \\
Females & 50 & $15 \cdot 3(2-45)$ & $40 \cdot 6(23-63)$ & 97 \\
Total & 132 & $14 \cdot 3(1-45)$ & $38 \cdot 2(20-63)$ & 92 \\
\hline
\end{tabular}

* Minimum and maximum values.

the Schober test and spondylometry were calculated only for patients examined by physicians at Troms $\emptyset$. Chest expansion was, however, measured by identical techniques by the different clinicians, and so the results from the patients at both hospitals were included. A history of acute anterior uveitis was accepted only when verified by an ophthalmologist. The occurrence of peripheral arthritis was accepted when the condition had been diagnosed by a physician.

Criteria for $A S$. The New York criteria ${ }^{12}$ for definite AS were applied, and only cases with $x$-ray changes of bilateral sacroiliitis were accepted as definite AS. Patients with juvenile onset of AS (less than 15 years), and patients with accompanying psoriasis or inflammatory bowel disease were excluded.

Roentgenological examination. Standard $x$-rays of the sacroiliac joints (anterioposterior and posterioanterior views) and the dorsolumbar junction (anterioposterior and lateral views) were preferred. $X$-ray films were available for all patients and were read by the same radiologist, who was unaware of the clinical status of the patients. For arthritic changes in the sacroiliac joints the grading system of Dale $^{16}$ was used. Only cases with definite changes (which corresponded to grade 3 or 4 of the New York criteria) were included in the present study. The content of the grading system is given in Table 2.

An observer variation study of this grading system has recently been published. ${ }^{17}$ Briefly, 96 films of the sacroiliac joints were evaluated by two radiologists. The films were randomly selected from an epidemiological survey of AS. The results showed that in $96.9 \%$ of the films the two observers agreed on whether definite arthritic changes were present or not. Eleven $x$-rays $(11.5 \%)$ were interpreted as showing suspicious changes by one observer, while the other radiologist regarded them as normal. In eight films $(8 \cdot 3 \%)$ the two observers differed with regard to the degree of abnormality but both interpreted these films as
Table 2 Radiological grading of sacroiliitis*

Grade 0: Normal conditions. With normal widths and sharp margins of the joints. A slight sclerosis of the ileum side of the joints may be present

Grade 1: Suspicious changes. The radiologist is uncertain whether there are changes described under grade 2

Grade 2: Definite early changes. Pseuod-widening of the joint space and/or localised areas with erosions. Sclerosis of the bone usually on both sides of the joint space. Blurring of the joint margins often present. 2a: Unilateral changes. $2 \mathrm{~b}$ : Bilateral changes.

Grade 3: Severe destructive changes. The erosions and often the pseudo-widening at least in one joint are more marked than in grade 2. The arthritic changes are always bilateral. Small bony bridges may be present.

Grade 4: Regressive changes. Bilateral arthritic changes as described under grade 3 , but in addition signs of narrowing of the joint space, often with bony bridges in one or both sacroiliac joints. Some regression of the sclerosis in the neighbourhood of the joint.

Grade 5: Terminal changes. Pronounced signs of bony ankylosis in both sacroiliac joints. Regression of the sclerosis in the neighbourhood of the joints.

* According to Dale. ${ }^{16}$

showing definite arthritic changes. In no instance did the two radiologists differ by more than one degree. Intraobserver variation was not tested in the study.

The morphological changes used to assess spinal $x$-ray involvement were: syndesmophytes, 'shining corners', squaring, arthritis of the apophyseal joints, spondylodiscitis, and 'bamboo spine'. When differentiation between osteophyte and syndesmophyte was difficult, the morphological change was termed mixtaosteophyte, and not counted as a radiological feature typical of AS.

HLA-B27 typing. The typing of HLA-B27 was performed according to techniques previously described. $^{18}$

Statistics. The $\chi^{2}$ test and Student's $t$ test were used, and a $p$ value of less than 0.05 was accepted as significant. The tests were done as two tails, and the alpha levels were not adjusted for the number of hypotheses tested. Correlations were determined by analysis of variance, and by $\chi^{2}$ test.

\section{Results}

Sacroiliac joints. Males had a slightly and nonsignificantly $(t=1 \cdot 5, \mathrm{df}=125, \mathrm{p}>0 \cdot 1)$ higher mean grade of $x$-ray changes in the sacroiliac joints (3.37) compared with females $(3 \cdot 10)$ (Table 3 ). $28 \%$ of the males and $16 \%$ of the females had complete 
Table 3 Correlation between disease duration and radiological changes of the sacroiliac joints and the lumbar spine in men and women

\begin{tabular}{|c|c|c|c|c|c|c|}
\hline \multirow[t]{2}{*}{$\begin{array}{l}\text { Disease } \\
\text { duration } \\
\text { (years) }\end{array}$} & \multicolumn{3}{|c|}{$\begin{array}{l}\text { Mean grade of } \\
\text { sacroiliac joint } \\
\text { changes }\end{array}$} & \multicolumn{3}{|c|}{$\begin{array}{l}\text { Frequency }(\%) \text { of } \\
\text { spinal } \mathrm{x}-\text {-ray } \\
\text { changes }\end{array}$} \\
\hline & Males & Females & Total & Males & Females & Total \\
\hline $1-5$ & $2 \cdot 5$ & $4 \cdot 3$ & $2 \cdot 8$ & $21 \cdot 4$ & 0.0 & $18 \cdot 8$ \\
\hline $6-10$ & $3 \cdot 2$ & $2 \cdot 8$ & $3 \cdot 1$ & $60 \cdot 0$ & $16 \cdot 7$ & $50 \cdot 0$ \\
\hline $11-15$ & $3 \cdot 7$ & $2 \cdot 9$ & $3 \cdot 3$ & $82 \cdot 4$ & $56 \cdot 3$ & $69 \cdot 7$ \\
\hline $16-20$ & 3.9 & $2 \cdot 6$ & $3 \cdot 3$ & $75 \cdot 0$ & $50 \cdot 0$ & $64 \cdot 3$ \\
\hline $21-30$ & $3 \cdot 8$ & $3 \cdot 5$ & 3.7 & $90 \cdot 9$ & $55 \cdot 6$ & $75 \cdot 0$ \\
\hline$>30$ & $4 \cdot 5$ & $4 \cdot 3$ & $4 \cdot 4$ & $100 \cdot 0$ & $100 \cdot 0$ & $100 \cdot 0$ \\
\hline Total & $3 \cdot 4$ & $3 \cdot 1$ & $3 \cdot 3$ & $74 \cdot 6$ & $44 \cdot 2$ & $62 \cdot 7$ \\
\hline
\end{tabular}

ankylosis (grade 5), but the difference was not statistically significant $\left(\chi^{2}=2 \cdot 4, \mathrm{df}=1, \mathrm{p}>0 \cdot 1\right)$.

Frequency of spinal $\mathrm{x}$-ray changes. The frequency of spinal $x$-ray changes is shown in Table 3 . Males had significantly more frequent radiological involvement of the spine $(74.6 \%)$ than females $(44.2 \%)$ $\left(\chi^{2}=10 \cdot 4, \mathrm{df}=1, \mathrm{p}<0 \cdot 01\right)$. It was noted that 'bamboo spine' was found twice as frequently in males $(14 \cdot 1 \%)$ as in females $(7 \cdot 0 \%)$, but this difference did not reach statistical significance $\left(\chi^{2}=1 \cdot 4, \mathrm{df}=1\right.$, $\mathrm{p}>0 \cdot 1)$. The most frequent spinal $x$-ray changes appearing in both sexes were syndesmophytes and squaring.

Correlation between duration of $A S$ and x-ray changes. There was a clear correlation between disease duration and degree of $x$-ray changes in the sacroiliac joints among both males (Table 3$)(t=8 \cdot 8$, $\mathrm{df}=73, \mathrm{p}<0.01)$ and females $(t=7.9, \quad \mathrm{df}=47$, $\mathrm{p}<0.01$ ).

A positive correlation between disease duration and radiological involvement of the spine was found in both men $\left(\chi^{2}=14.9, \mathrm{df}=2, \mathrm{p}<0.01\right)$ and women $\left(\chi^{2}=5 \cdot 4, d f=2, p<0 \cdot 02\right)$ (Table 3$)$. As many as $60 \%$ of the males, but only $16 \cdot 7 \%$ of the females had $x$-ray changes in the lumbar spine after a disease

Table 4 Sacroiliac joint changes and lumbar mobility in men and women with $A S$

\begin{tabular}{|c|c|c|c|c|c|c|}
\hline \multirow{2}{*}{$\begin{array}{l}\text { Schober's } \\
\text { test } \\
(\mathrm{cm})\end{array}$} & \multicolumn{2}{|c|}{ Males } & \multicolumn{2}{|c|}{ Females } & \multicolumn{2}{|c|}{ Total } \\
\hline & No. & Mean & No. & Mean & No. & Mean \\
\hline $0 \cdot 0-1 \cdot 0$ & 12 & $4 \cdot 8$ & 7 & $3 \cdot 6$ & 17 & 4.4 \\
\hline $1 \cdot 1-2 \cdot 0$ & 11 & 2.9 & 6 & 3.7 & 17 & $3 \cdot 2$ \\
\hline $2 \cdot 1-3 \cdot 0$ & 13 & 3.0 & 11 & $3 \cdot 2$ & 24 & $3 \cdot 1$ \\
\hline $3 \cdot 1-4 \cdot 0$ & 14 & $3 \cdot 2$ & 13 & $2 \cdot 7$ & 27 & $3 \cdot 0$ \\
\hline $4 \cdot 1-4 \cdot 5$ & 2 & $3 \cdot 0$ & 1 & $2 \cdot 0$ & 3 & $2 \cdot 7$ \\
\hline$>4.5$ & 17 & $2 \cdot 5$ & 4 & $3 \cdot 0$ & 21 & $2 \cdot 6$ \\
\hline
\end{tabular}

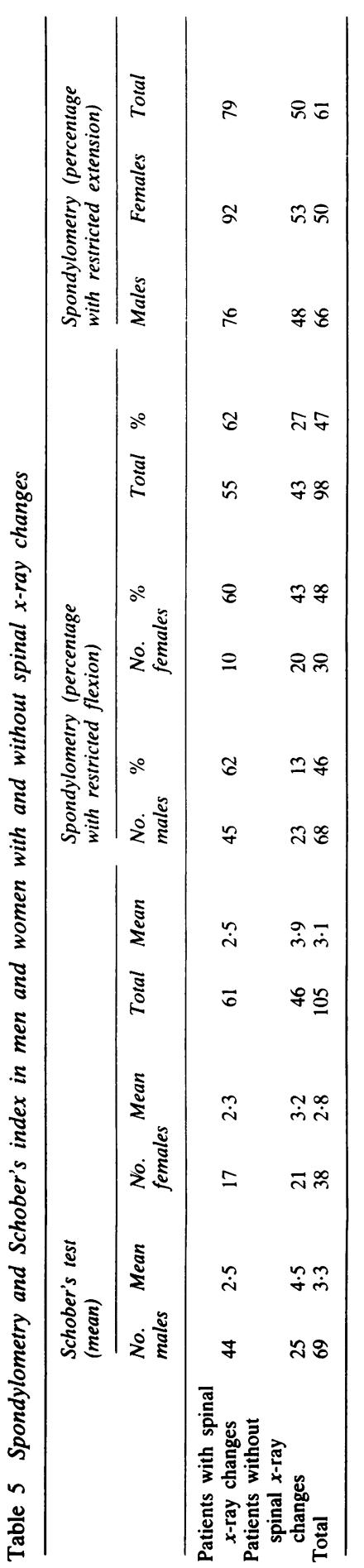


duration of $6-10$ years (Table 3$)\left(\chi^{2}=3 \cdot 5, \mathrm{df}=1\right.$, $\mathrm{p}<0.05)$.

Correlation between spinal and chest mobility and $\mathrm{x}$-ray changes. A clear correlation between grade of sacroiliac changes and restricted lumbar mobility was found both in males $(t=8.5, \mathrm{df}=72, \mathrm{p}<0.01)$ and in females $(t=6 \cdot 3, \mathrm{df}=41, \mathrm{p}<0 \cdot 01)$ (Table 4). The mean grade of sacroiliac joint changes among male patients with normal Schober's index $(>4.5$ $\mathrm{cm}$ ) was 2.5 compared with 4.8 in those with a Schober's index of $0-1 \mathrm{~cm}$, which means a difference in the $x$-ray grading of $2 \cdot 3(t=9 \cdot 2, \mathrm{df}=27, \mathrm{p}<0 \cdot 01)$. The corresponding difference in females was only $0.6(t=1 \cdot 6, \mathrm{df}=9, \mathrm{p}>0 \cdot 1)$. Both male and female patients with spinal $x$-ray changes had more restricted lumbar mobility than those without such radiological changes. This difference was more pronounced in males than in the females (Table 5), and the difference reached statistical significance only in males $\left(\chi^{2}=9 \cdot 0, \mathrm{df}=1, \mathrm{p}<0.01\right)$. Among patients with spinal $x$-ray changes $84.8 \%$ of the males had restricted Schober's index (less than 4.5 $\mathrm{cm}$ ), the figure in females being $94 \cdot 1 \%$. The relative frequency of restricted Schober's index among those without these radiological features was $50 \%$ in males and $85.7 \%$ in females.

A significantly higher frequency of restricted total spinal flexion as measured by spondylometry was found in males with spinal $x$-ray changes compared with males without such changes (Table 5) $\left(\chi^{2}=14 \cdot 8, \mathrm{df}=1, \mathrm{p}<0 \cdot 001\right)$, while no such difference was found in females $\left(\chi^{2}=0 \cdot 6, \mathrm{df}=1, \mathrm{p}>0 \cdot 10\right)$. However, a significant difference with respect to spinal extension was found both in males $\left(\chi^{2}=5 \cdot 2\right.$, $\mathrm{df}=1, \mathrm{p}<0.05)$ and females $\left(\chi^{2}=4 \cdot 8, \mathrm{df}=1, \mathrm{p}<0.05\right)$ (Table 5). The mean chest expansion was $4.10 \mathrm{~cm}$ in males and $4 \cdot 14 \mathrm{~cm}$ in females. Male patients without spinal $x$-ray changes had a significantly higher mean chest expansion $(5.2 \mathrm{~cm})$ than males with such features $(3 \cdot 5 \mathrm{~cm})(t=3 \cdot 1, \mathrm{df}=62, \mathrm{p}<0 \cdot 01)$. A corresponding difference in chest expansion was not observed among the female AS patients, the figures being $4.3 \mathrm{~cm}$ and $4.0 \mathrm{~cm}$ respectively $(t=0 \cdot 3, \mathrm{df}=20$, $\mathrm{p}>0.5$ ).

Symphysis pubis. Definite arthritic changes in the symphysis pubis was found in four out of $\mathbf{4 3}$ females $(9.3 \%)$, but in none of the males, the difference being highly significant $(t=7 \cdot 5, \mathrm{df}=120, \mathrm{p}<0.01)$.

\section{Discussion}

We have previously compared various clinical features of AS in males and females without observing significant differences between the two sexes. ${ }^{11}$ The present study compared males and females with respect to possible differences as expressed by the radiological appearances of the disease. Both studies were designed to explain the presumed under-estimation of AS in females.

The males and females studied were not perfectly comparable. First, the male AS patients were selected from our rheumatic disease unit while some of the females originated from another unit. Although the 23 females from the other hospital were consecutively selected and their $x$-rays were judged by the same radiologist, the difference of selection may have introduced a bias into the study. Another point of importance was that 22 out of 82 male AS patients $(27 \%)$ were taken from an epidemiological survey, whereas only 5 of 50 females $(10 \%)$ were selected this way.

As previously shown by us, ${ }^{17} \mathrm{AS}$ patients found in population surveys tend to have milder disease than those attending hospital. Less severe disease would thus be expected among the male patients. Furthermore, the females had a longer disease duration and a higher mean age than the males, and hence the radiological involvement would be expected to be more severe in females.

Interpretation of $x$-rays of the sacroiliac joints is difficult and may be hampered by both inter- and intraobserver variation. ${ }^{19-21}$ In the present study plain films of the sacroiliac joints were preferred. It has been shown that oblique views do not offer any advantage to the interpretation of arthritic changes in these joints. ${ }^{19,22} \mathrm{~A}$ series of views could possibly have reduced the extent of intraobserver variation, ${ }^{19}$ but unfortunately a series of films was available only for a few patients. Thus the results of the present study were not corrected for possible intraobserver variation error, but we think it unlikely that interpretation and grading of the sacroiliac joint changes should have been greater in one sex rather than the other.

Although the differences did not reach statistical significance, there was a clear tendency for the males to have more severe arthritic changes in the sacroiliac joints than females. However, even when the above mentioned differences of selection and possible biases are taken into account, these results suggest that males may have more severe radiological arthritic changes in the sacroiliac joints than females.

Radiological spondylitic changes in the lumbar spine were significantly more frequent among males than females. No particular spondylitic change appeared to be responsible for this difference, although the classical 'bamboo spine' was found twice as often in males as in females. In agreement with others ${ }^{6-8}$ our findings thus suggest a more extensive disease in males than in females. The frequency of radiological involvement of the lumbar 
spine $(44 \%)$ in females was comparable with the estimated frequency of $40 \%$ determined in two previous studies. ${ }^{68}$ Other studies ${ }^{923}$ have, however, found an even higher prevalence $(51.6 \%$ to $56 \%$ ) of $x$-ray abnormalities in the lumbar spine of females with AS. Only one ${ }^{9}$ of these four investigations ${ }^{6} 8923$ contained both information on male AS patients and statements concerning mean disease duration of AS. Mean disease duration of the females in the present study ( 15.3 years) was similar to that of 15 years among the females in the study of Resnick and coworkers. ${ }^{9}$ The difference in frequency of $x$-ray changes in the lumbar spine between these two studies, $44 \cdot 2 \%$ versus $56 \%$ respectively, can probably be best explained by different procedures for selection of patients.

Unfortunately we did not have an opportunity of studying changes eventually occurring in the dorsal and cervical spine. It has been suggested ${ }^{8}{ }^{9}$ that isolated cervical spine involvement tends to be the more frequent among female AS patients. Another radiological feature reported to be relatively frequent in female AS is the arthritic involvement of the symphysis pubis. ${ }^{689}$ This was found in $9.3 \%$ of our female AS patients and in none of the males. It is, however, difficult to compare this result with previous investigations in which the frequency of radiological arthritis of the symphysis pubis varied between zero and $61 \% .{ }^{68924}$ Reliable comparisons are hampered by the fact that many earlier studies have investigated females only and have often included patients with primary AS, juvenile onset AS, Reiter's disease, psoriatic arthropathy, and AS associated with inflammatory bowel diseases.

The tendency for less extensive involvement among females might be one of the reasons for the suggested underestimation of AS occuring in this sex. The present findings also contrast with our previous observations ${ }^{11}$ of no obvious difference between the two sexes with respect to the clinical features of AS. This apparent paradox could be explained by a lack of correlation beween the clinical findings and the radiological feature of AS.

Positive correlations between disease duration and severity of spinal $x$-ray changes were observed both in males and in females. Furthermore a significant correlation between restriction of lumbar mobility and degree of sacroiliac arthritis was found in both sexes, but further analysis indicated a stronger correlation between reduced lumbar mobility and radiological sacroilitis in males than in females. The same tendency appeared to occur with respect to changes in the lumbar spine and restriction of total spinal mobility.

In males there was also a significant association between restricted chest expansion and the degree of $x$-ray changes in the lumbar spine, while this correlation was not found among women. These observations may indicate that in females factors other than the inflammatory process visualised by $x$-ray may be decisive in causing restricted mobility of the spine and the chest. These results should be seen in light of the possible biases of interobserver variation errors in the clinical measurements. ${ }^{1325}$ We do find it unlikely, however, that under- or overestimation affected one of the sexes more than the other.

From the present investigation we tentatively suggest that males with AS have more severe and widespread disease than females as judged radiologically. As previously shown, ${ }^{11}$ however, this difference is not reflected by the clinical expression of this rheumatic disorder in the two sexes.

This work was supported by the Norwegian Research Councils for Science and Humanities, the Norwegian Women's Health Association, and the Norwegian Rheumatism Council.

\section{References}

1 West H F. The aetiology of ankylosing spondylitis. Ann Rheum Dis 1949; 8: 143-8.

2 Polley H F, Slocumb C M. Rheumatoid spondylitis: a study of 1035 cases. Ann Intern Med 1947; 26: 240-9.

3 von Mach J. Zum Vorkommen der Spondylarthritis ankylopoetica beim weiblichen Geschlecht. Beitr Orthop Traumatol 1974; 21: 241-7.

4 Tandberg A. Initial symptoms in spondylarthritis ankylopoetica. Rheumatism 1950; 6: 127-32.

5 Calin A, Fries J F. Striking prevalence of ankylosing spondylitis in 'healthy' w27 positive males and females. A controlled study. $N$ Engl $J$ Med 1975; 293: 835-9.

6 Hart F D, Robinson K C. Ankylosing spondylitis in women. Ann Rheum Dis 1959; 18: 15-23.

7 Jeannet M, Saudan Y, Bitter T. HL-A27 in female patients with ankylosing spondylitis. Tissue Antigens 1975; 6: 262-4.

8 Tyson T L, Thompson W A L, Ragan C. Marie-Strümpell spondylitis in women. Ann Rheum Dis 1953; 12: 40-2.

9 Resnick D, Dwosh I L, Coergen T G, et al. Clinical and radiographic abnormalities in ankylosing spondylitis: a comparison of men and women. Diag Radiol 1976; 119: 293-7.

10 Hill H F H, Hill A G S, Bodmer J G. Clinical diagnosis of ankylosing spondylitis in women and relation to presence of HLA-B27. Ann Rheum Dis 1976; 35: 267-70.

11 Gran J T, Østensen M, Husby G. A clinical comparison between males and females with ankylosing spondylitis. $J$ Rheumatol in press.

12 Bennet P H, Burch T A. New York symposium on population studies in rheumatic diseases: new diagnostic criteria. Bull Rheum Dis 1967; 17: 453-8.

13 Macrae I F, Wright V. Measurement of back movement. Ann Rheum Dis 1967; 8: 584-91.

14 Hart F D, Strickland D, Cliffe P. Measurements of spinal mobility. Ann Rheum Dis 1974; 33: 136-9.

15 Moll J M H, Wright V. The pattern of chest and spinal mobility in ankylosing spondylitis. Rheumatol Rehabil 1973; 12: 115-34.

16 Dale K. Radiographic grading of sacroiliitis in Bechterew's syndrome and allied disorders. Scand J Rheumatol 1980; 32: (suppl) 92-7. 
17 Gran J T. Husby G. Ankylosing spondylitis. A comparative study of patients found in an epidemiological survey, and those admitted to a department of rheumatology. $J$ Rheumatol in press.

18 Gran J T. Smith-Mellby A. Husby G. The prevalence of HLA-B27 in Northern Norway. Scand J Rheumatol in press.

19 Ryan L M, Carrera G F. Lightfoot R W. Hoffman R G, Kozin $F$. The radiographic diagnosis of sacroiliitis. A comparison of different views with computed tomograms of the sacroiliac joint. Arthritis Rheum 1983; 26: 760-3.

20 Macrac I F. Haslock D I. Wright V. Grading of films sacroiliitis in population studies. Ann Rheum Dis 1971; 30: 58-66.

21 Hollingsworth P N, Cheah P S, Dawkins R L, Owen E T, Calin A. Wood $\mathrm{P} H \mathrm{~N}$. Observer variation in grading sacroiliac radiographs in HLA-B27 positive individuals. $J$ Rheumatol 1983: 2: 247-54.

22 Grainger R G. Radiological aspects of sacro-iliac arthritis. Proc $R$ Soc Med 1957: 50: 854-8.

23 Nasseh G. Saudan Y. La pelveospondylite rheumatismalc (spondylite ankylosante) chez la femme (étude clinique et radiologique de 31 cas). Med Hyg (Genève) 1975: No 1143: 554-7.

24 McBryde A M. McCollum D E. Ankylosing spondylitis in women. The disease and its prognosis. $N C$ Med J 1973: 34: 34-7.

25 Sturrock R D, Wojtulewski J A, Dudley Hart F. Spondylometry in a normal population and in ankylosing spondylitis. Rheumatol Rehabil 1973; 12: 135-42. 